\title{
DESKRIPSI KONDISI HABITAT SIAMANG, Symphalangus syndactylus, DI HUTAN LINDUNG REGISTER 28 PEMATANG NEBA KABUPATEN TANGGAMUS LAMPUNG
}

\author{
Bunga Indah Permatasari, Agus Setiawan, Arief Darmawan
}

Fakultas Pertanian, Universitas Lampung, Jalan Soemantri Brojonegoro No.1 Bandar Lampung

\section{A B S T RACT}

The Siamang, Symphalangus syndactylus, an arboreal black-furred gibbon member of the family Hylobatidae is listed as an endangered species by IUCN since 2008. The main threat to Siamang is the degraded habitat in term of quality and extent due to fragmentation. Protected forest Register 28 Pematang Neba located in Kabupaten Tanggamus is an example of the Siamang habitat threatened by the surrounding land conversion. This study aimed to determine the vegetation structure and profile of the Siamang habitat and to determine the diversity and abundance of plants the diet of Siamang. This study was a survey, and the observation was conducted from July to August 2017 applying three belt transect in the Protected Forest Register 28 Pematang Neba. The vegetation structure and profile of the Siamang habitat showed the distance between trees was more than $4 \mathrm{~m}$ that influence the Siamang activity in foraging, resting, and playing. The IVI showed a moderate category at the level of $130.813 \%, 135.948 \%$, and $122.98 \%$ for Habitat 1 , 2, and 3 accordingly. The diversity index showed a moderate category at the level of 2.905 and 2.762 for Habitat 1 and 2 respectively, and a high category for Habitat 3 at the level of 3.066. The similarity index values among habitats were considered high (69-81\%) allowing Siamang to migrate between habitats. The variety of Siamang diet was composed of leaves, fruits, and flowers.

KEY WORDS: abundance, habitat, Siamang, structure and profile of vegetation

Penulis korespondensi: BUNGA INDAH PERMATASARI | email: psbunga@yahoo.com

Dikirim: 01-11-2017 | Diterima: 11-12-2017

\section{PENDAH UL UA N}

Peraturan Pemerintah Republik Indonesia (Departemen Kehutanan, 1999) tentang Pengawetan Tumbuhan dan Satwa menyatakan bahwa semua satwa famili Hylobatidae dilindungi, dan salah satunya adalah Siamang (Symphalangus syndactyilus). Berdasarkan data IUCN Red List 2008, siamang termasuk dalam kategori terancam punah (endangered) (Geissman \& Nijman, 2006; Kwatrina et al., 2013).

Ancaman utama yang dihadapi populasi siamang adalah penurunan kuantitas dan kualitas habitat karena terjadinya fragmentasi habitat. Fragmentasi tersebut terjadi sebagai akibat pembukaan kawasan hutan dan lahan untuk perkebunan, yang menyebabkan populasi siamang terdesak pada habitat dan wilayah yang sempit. Populasi siamang di Sumatera yang tersisa saat ini sebagian besar terdapat di kawasan hutan lindung (HL) dan konservasi (Geissman \& Nijman, 2006; Kwatrina et al., 2013).

Lampung termasuk wilayah yang memiliki HL, salah satunya adalah HL Register 28 Pematang Neba, yang dari tahun ke tahun luasannya semakin berkurang diakibatkan oleh konversi lahan yaitu perubahan lahan hutan menjadi lahan perkebunan. Kawasan tersebut pada umumnya merupakan kawasan yang berbatasan langsung dengan lahan masyarakat (hutan kemasyarakatan), sehingga rentan mengalami alih fungsi lahan (Zahra, 2016). Hal ini membuat tekanan terhadap siamang seperti hilangnya tutupan lahan yang dijadikan cover (tempat berlindung), berkurangnya sumber pakan bagi siamang dan berkurangnya populasi siamang.

Deskripsi kondisi habitat siamang diperlukan untuk perlindungan siamang dan habitatnya.
Penelitian ini bertujuan untuk menganalisis struktur dan profil vegetasi habitat, mengidentifikasi jenis tumbuhan pakan siamang dan kelimpahannya, serta menganalisis perbandingan antarhabitat di HL Register 28 Pematang Neba.

\section{MET ODE}

HL Register 28 Pematang Neba merupakan salah satu HL yang berada di Kabupaten Tanggamus. Luas HL ini adalah $13.419,85$ ha. Berada pada ketinggian 300 sampai $600 \mathrm{dpl}$. Kondisi tanah sebagaian besar berupa daerah perbukitan dan daerah yang masih masuk katagori landai, kelerengan lahan bervariasi mulai dari datar (0-3\%), miring (15-30\%), agak curam (30-45\%), dan curam (45-65\%).

Objek yang diteliti adalah keberadaan siamang dan vegetasi HL Register 28 Pematang Neba. Alat yang digunakan meliputi, binokuler, Geographically Positioning System (GPS), kompas, tali, pastik, patok kayu, meteran, Cristen Hypsometer, tally sheet, kamera dan ATK.

Pengumpulan data tentang keberadaan siamang diperoleh dengan menggunakan metode observasi. Data struktur dan profil vegetasi siamang diambil pada tiga lokasi yaitu Habitat 1 (52 28' 14.7504", 104 ${ }^{\circ} 44^{\prime}$ 50.8988"), Habitat 2 (5०28' 25.5971", $\left.104^{\circ} 45^{\prime} 09.9388^{\prime \prime}\right)$, dan Habitat 3 (5०28' 25.5971", $104^{\circ}$ 45'09.9388") (Gambar 1) menggunakan metode jalur. Pada metode jalur (petak contoh) dibuat petak contoh berbasis pada plot persegi yang umumnya dibuat tegak lurus garis kontur (Heyne, 1987) selanjutnya digambarkan secara vertikal dan horizontal serta dianalisis secara deskriptif sehingga diperoleh struktur dan profil vegetasi yang mewakili habitat siamang tersebut. Data jenis pakan siamang diperoleh melalui metode observasi langsung dan metode jalur. Observasi langsung dilakukan dengan mengamati jenis-jenis tumbuhan pakan yang teramati dikonsumsi oleh siamang selama penelitian, dan didukung dengan studi kepustakaan.

Data sekunder adalah data penunjang penelitian dengan menggunakan metode studi kepustakaan yaitu metode yang digunakan untuk mencari, menganalisis dan mengumpulkan 


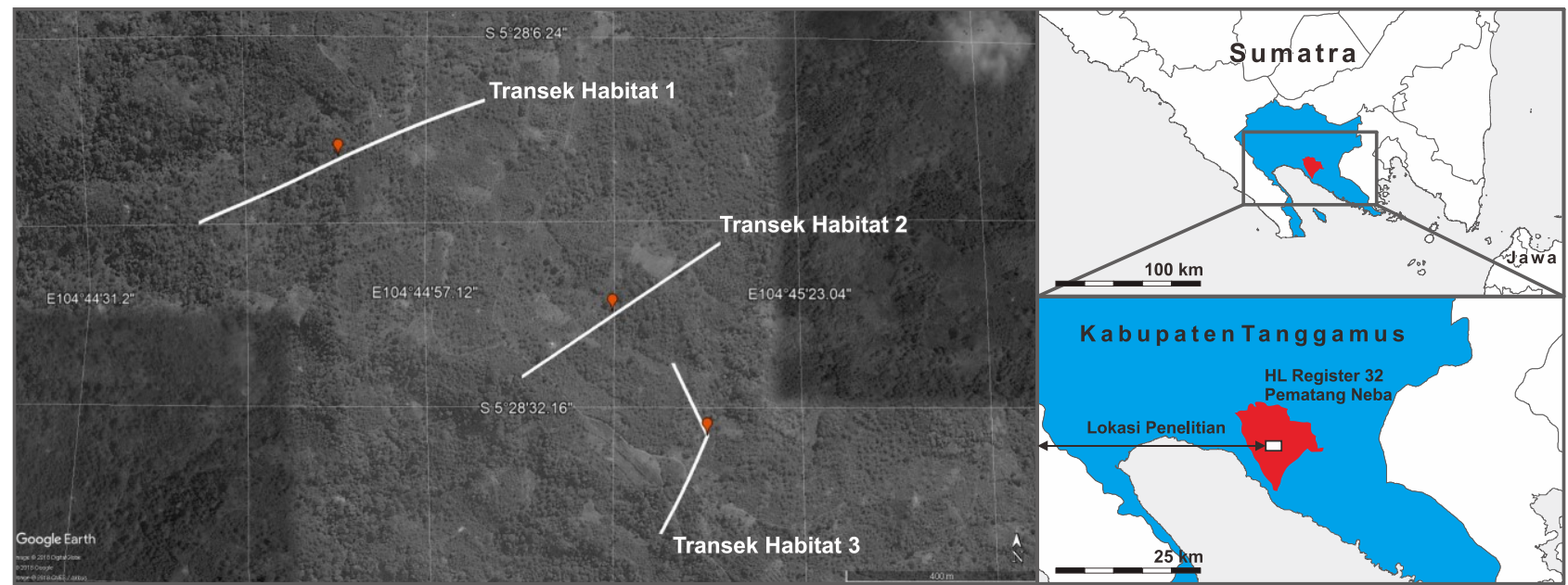

Gambar 1. Peta transek pengambilan petak contoh (plot) pada habitat Siamang di HL Register 28 Pematang Neba

data dengan mempelajari buku-buku, skripsi dan jurnal penelitian yang berhubungan dengan penelitian ini. Analisis data pada penelitian ini meliputi analisis vegetasi, analisis struktur dan profil vegetasi siamang, analisis jenis pakan siamang dan analisis perbandingan habitat siamang menggunakan Indeks Keanekaragaman dan Indeks Kesamaan Komunitas. Data yang dikumpulkan berupa tinggi pohon, diameter batang, dan lebar tajuk pohon. Struktur pohon digambarkan secara vertikal dan horizontal serta dianalisis secara deskriptif sehingga diperoleh profil vegetasi yang mewakili habitat siamang tersebut.

Data yang diperoleh dari pengamatan dilakukan analisis vegetasi sehingga diperoleh kerapatan relatif, frekuensi relatif, dan dominansi relatif. Dalam analisis vegetasi tumbuhan pakan digunakan persamaan yang sama dengan analisis struktur vegetasi siamang. Hasil yang diperoleh dianalisis secara deskriptif kuantitatif sehingga diketahui jenis dan kelimpahan tumbuhan pakan siamang di HL Register 28. Keanekaragaman jenis dapat diketahui dengan Indeks Keanekaragaman Shannon-Wienner (Odum, 1971; Fachrul, 2007). Kriteria tingkat keanekaragaman yang menjadi rujukan adalah bila nilai indeks $H^{\prime}<1$ termasuk tingkat keanekaragaman rendah, nilai indeks $H^{\prime}=1-3$ termasuk tingkat keanekaragaman sedang, dan nilai indeks $H^{\prime}>3$ termasuk tingkat keanekaragaman tinggi. Perbandingan antar habitat berdasarkan komposisi jenis dapat diketahui dengan Indeks Kesamaan Komunitas (Odum, 1971), dengan kriteria jika IKK < 50\% tergolong mempunyai kesamaan rendah, sedangkan bila nilai IKK > $50 \%$ tergolong memiliki kesamaan tinggi.

\section{HASIL DAN PEMBAHASAN}

Profil vegetasi tumbuhan merupakan gambaran profil vertikal dan horizontal serta struktur dan komposisi jenis dari suatu vegetasi yang meliputi dominansi penutupan tajuk, model arsitektur pohon, keanekaragaman jenis, dominasi jenis, frekuensi jenis, kerapatan jenis, indeks nilai penting jenis pohon/INP, dan tumbuhan bawah yang ada di dalam suatu vegetasi (Setiadi, 1998).

Profil vegetasi pada Habitat 1 menunjukkan bahwa tutupan tajuk pada Habitat 1 di HL Register 28 Pematang Neba ini tidak rapat (Gambar 2). Habitat 1 ini memiliki kelimpahan (INP) yang termasuk dalam katagori rendah. Hal tersebut dilihat dari kerapatan, frekuensi dan dominansi yang rendah pada setiap jenis pohon yang teramati (Gambar 3). Hal tersebut berpengaruh untuk aktivitas siamang seperti mencari makan, istirahat, dan bermain atau berpindah karena siamang adalah kelompok primata sejati hutan yang membutuhkan pohon dalam beraktivitas (Larasati, 2009). Siamang tidak jauh berbeda dengan keluarga Hylobates yang lain misalnya owa Jawa (Hylobates moloch), dimana pergerakan satwa ini dilakukan dengan berayun (brankiasi) dari satu pohon ke pohon lain dengan jarak mencapai lebih dari $10 \mathrm{~m}$ (Supriatna \& Wahyono, 2000).

INP memiliki kisaran skala $0-300$; skala 0-100 termasuk ke dalam kategori rendah, skala 101-200 termasuk ke dalam kategori sedang dan untuk 201300 termasuk ke dalam kategori tinggi (Indriyanto, 2006). Kelimpahan jenis di Habitat 1 pada masingmasing jenis pohon hanya berkisar 5,89-44,59\% yang berarti INP berada dalam katagori rendah. Gambar 3 menunjukkan bahwa INP tertinggi yaitu pohon nomor 2, walek angin (Mollus paniculatus), sebesar 44,59\% yang menunjukkan pohon walek angin memiliki dominansi tinggi di Habitat 1. Indriyanto (2006) dalam Desi et al. (2017) menyatakan bahwa INP yang tinggi menunjukkan spesies dominan dalam komunitas tumbuhan. INP suatu jenis menggambarkan tingkat dominansinya terhadap jenis-jenis lain dalam suatu komunitas. Jenis yang mempunyai INP tertinggi berpeluang lebih besar untuk dapat mempertahankan pertumbuhan dan kelestarian jenisnya (Mawazin \& Subiakto, 2013).

Smith (1977) mengemukakan bahwa jenis yang dominan adalah jenis yang dapat memanfaatkan lingkungan yang ditempati secara efisien dibanding jenis lain dalam tempat yang sama. Jenis yang mempunyai INP lebih tinggi akan lebih stabil, dilihat dari sisi ketahanan jenis dan pertumbuhannya. Sutisna (1981) mengemukakan semakin tinggi INP suatu jenis, maka keberadaan jenis tersebut semakin stabil.

Struktur vegetasi pada Habitat 1 berada pada strata tengah dengan ketinggian pohon berkisar 14$24 \mathrm{~m}$. Siamang lebih banyak menggunakan strata menengah untuk aktivitasnya karena tajuk pohon 
pada strata tengah memiliki cabang lateral yang bersinggungan, membentuk kanopi yang tertutup, yang memudahkan siamang berpindah dari satu pohon ke pohon lainnya (Yuliana, 2011).

Aktivitas kelompok siamang, baik aktivitas bergerak, bersuara maupun makan, sangat dipengaruhi oleh cuaca. Siamang lebih memilih untuk berteduh di dahan pohon dengan ketinggian di atas 30 meter ketika hujan sehingga jika turun hujan pada pagi hari, suara siamang tidak terdengar sama sekali. Dari hasil penelitian, saat cuaca hujan, kelompok siamang pada umumnya akan bersuara kembali ketika hujan reda dan matahari mulai muncul. Jarak jelajah siamang juga sangat berpengaruh ketika sedang hujan. Siamang pada umumnya hanya bergerak di sekitar pohon dengan ketinggian lebih dari 30 meter dan dengan tajuk yang rapat. Kelompok siamang ini memiliki insting yang cukup tinggi terhadap cuaca. Ketika cuaca mulai mendung, kelompok siamang ini akan mempercepat aktivitasnya dan bergerak ke bagian hutan yang lebih aman dan tidak jauh dari pohon tidurnya (Sari \& Harianto, 2015).

Berdasarkan pengamatan di Habitat 1, terdapat 9 jenis tumbuhan yang menjadi tempat bermain dan beristirahat siamang yaitu gamal (Gliricidia sepium), bambu (Bamboo sp.), anggrong (Irema orientalis), pasang (Quercus sundaica), winong (Tetrameles nudiflora), bendo (Artocarpus elasticus), cempaka (Michelia champacca), ketapang (Terminalia catappa), mindi (Melia azedarach). Pohon tidur yang tinggi dan bertajuk lebar memberikan rasa aman bagi siamang terhadap gangguan predator dan membantu siamang dalam mengamati teritorinya (Yuliana, 2011). Pada saat istirahat siamang menghindari terik sinar matahari dengan cara turun ke bagian tajuk yang paling rendah (Tiyawati et al., 2016). Tumbuhan yang dimakan oleh siamang yaitu aren (Arenga pinnata), walek angin (Mallotus paniculatus), kemiri (Aleurites moluccanus), jengkol (Pitchelobium lobatum), rambutan hutan (Nephelium mutabile), petai cina (Leucaena leucocephala), matoa (Pometia pinnata), dan gondang (Ficus fariegata). Primata umumnya memilih lokasi untuk mencari pakan pada bagian tengah dan bagian atas tajuk pohon (Suyanto et al., 2009). Iskandar (2007) yang dikutip oleh Bangun et al. (2009) menyatakan bahwa jenis pohon yang digunakan sebagai pohon tempat tidur primata adalah jenis pohon yang pada umumnya juga dimanfaatkan sebagai pohon sumber pakan.

Profil vegetasi pada Habitat 2 menunjukkan adanya jarak antarpohon yang membuat siamang terganggu untuk melakukan aktivitas (Gambar 4). Jarak tersebut dikarenakan adanya lahan garapan masyarakat pada habitat siamang sehingga membuat siamang kesulitan berpindah dari pohon satu ke pohon lainnya. Hal ini dibuktikan dengan rendahnya kelimpahan masing-masing jenis pohon yang ada pada lokasi tersebut yang hanya berkisar sebesar 5,81-57,96\% (Gambar 5). Struktur vegetasi pada Habitat 2 ini berada pada strata tengah dengan tinggi pohon 14-25 m.

INP tertinggi dimiliki oleh pohon nomor 6 yaitu pohon walek angin (Mallotus paniculatus) (Gambar 3), hal tersebut menunjukkan bahwa pohon walek angin memiliki dominansi yang tinggi. Menurut Maisyaroh (2010) dalam Erwin et al. (2017), jenis dominan mempunyai tingkat kesesuaian terhadap tempat tumbuh (daya adaptasi) dan daya kompetisi yang lebih baik dibandingkan dengan jenis lain pada lahan tersebut.

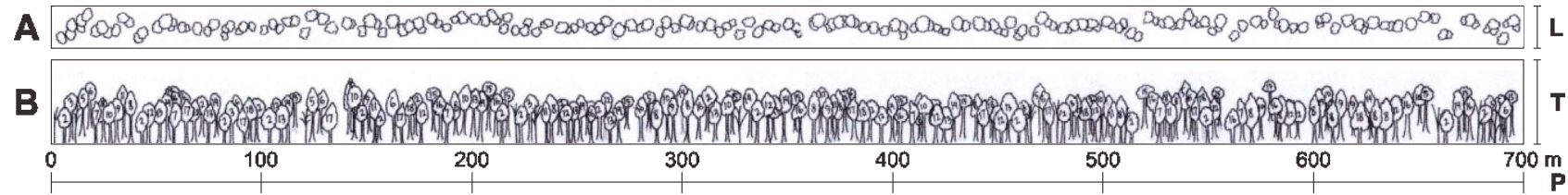

Gambar 2. Profil vegetasi Habitat 1 Siamang, Symphalangus syndactyilus, di HL Register 28 Pematang Neba Keterangan: A = Profil vegetasi secara horizontal (kerapatan tajuk), B = Profil vegetasi secara vertikal (tinggi pohon dan kerapatan pohon), Bidang areal pengamatan $\mathrm{P}=$ panjang $700 \mathrm{~m}, \mathrm{~L}=$ lebar $20 \mathrm{~m}$, dan $\mathrm{T}=$ tinggi pohon $14-24 \mathrm{~m}$

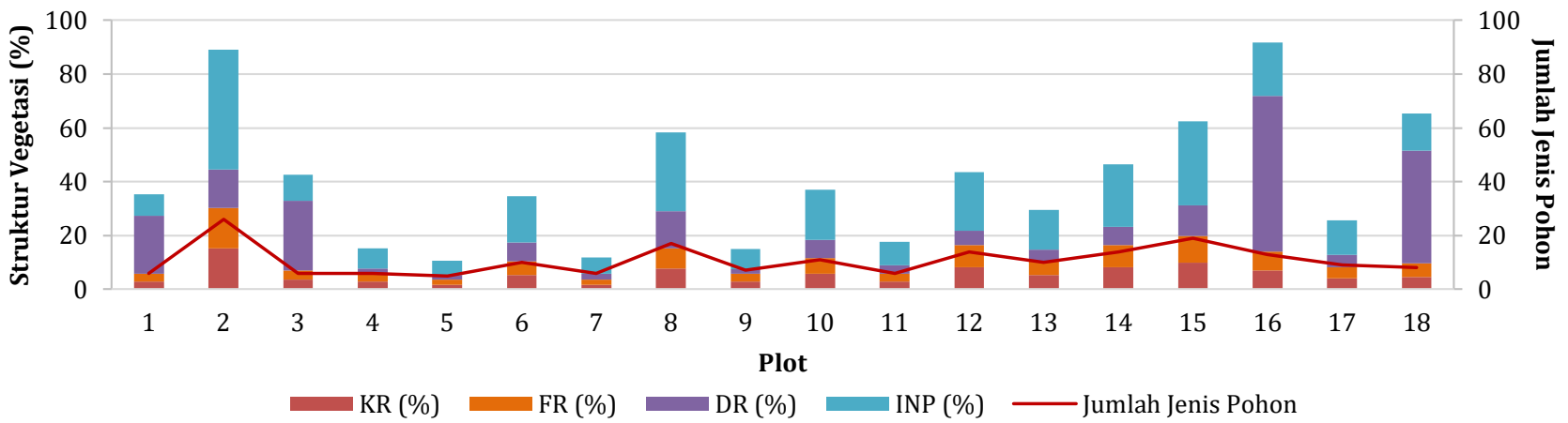

Gambar 3. Grafik Jumlah Jenis Pohon, Kerapatan Relatif, Frekuensi Relatif, Dominansi Relatif, dan INP antar plot yang terdapat di Habitat 1 HL Register 28 Pematang Neba 


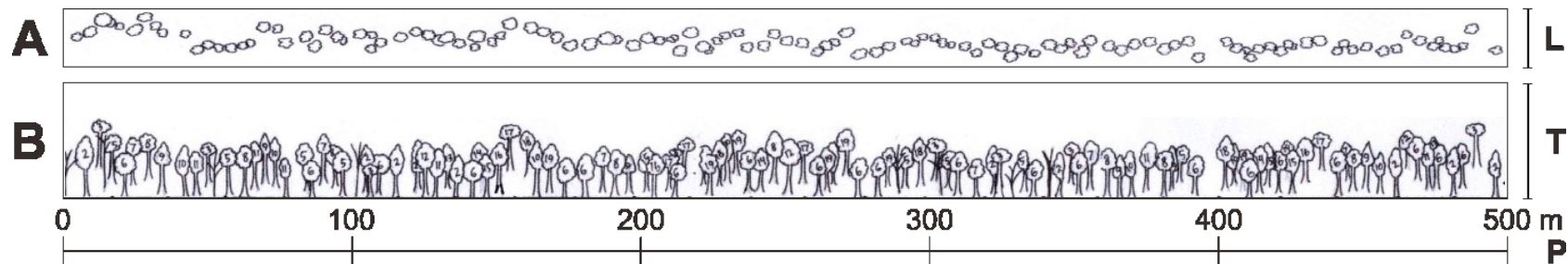

Gambar 4. Profil vegetasi Habitat 2 Siamang, Symphalangus syndactyilus, di HL Register 28 Pematang Neba Keterangan: A = Profil vegetasi secara horizontal (kerapatan tajuk), B = Profil vegetasi secara vertikal (tinggi pohon dan kerapatan pohon), Bidang areal pengamatan $\mathrm{P}=$ panjang $500 \mathrm{~m}, \mathrm{~L}=$ lebar $20 \mathrm{~m}$, dan $\mathrm{T}=$ tinggi pohon $14 \mathrm{~m}-25 \mathrm{~m}$

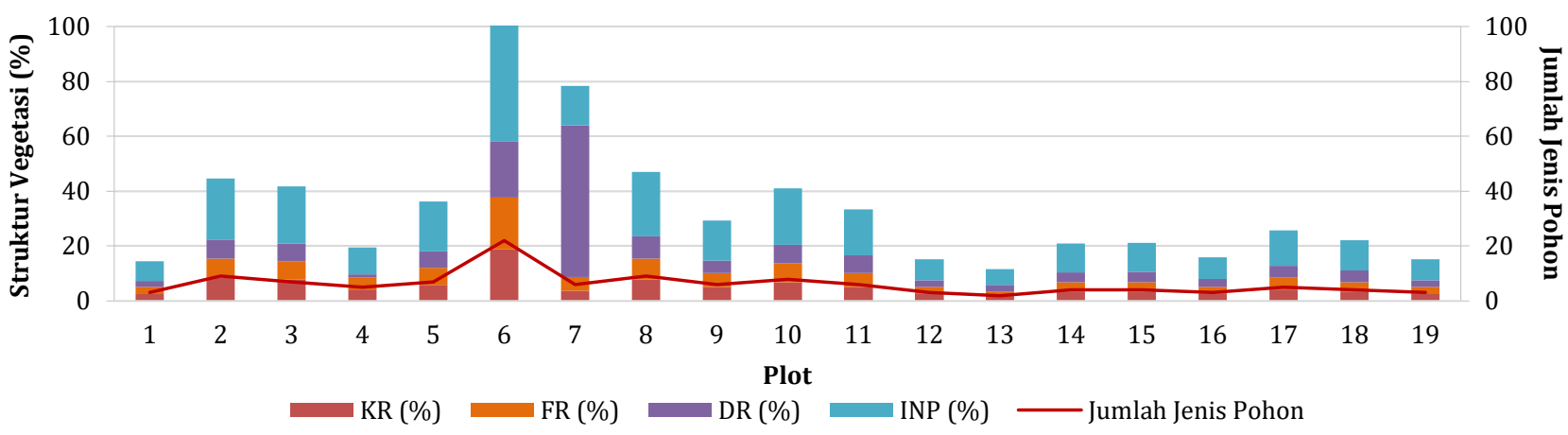

Gambar 5. Grafik Jumlah Jenis Pohon, Kerapatan Relatif, Frekuensi Relatif, Dominansi Relatif, dan INP antar plot yang terdapat di Habitat 2 HL Register 28 Pematang Neba

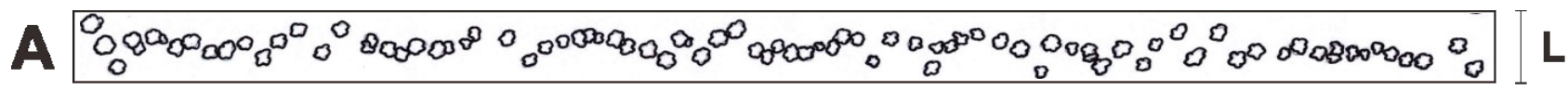

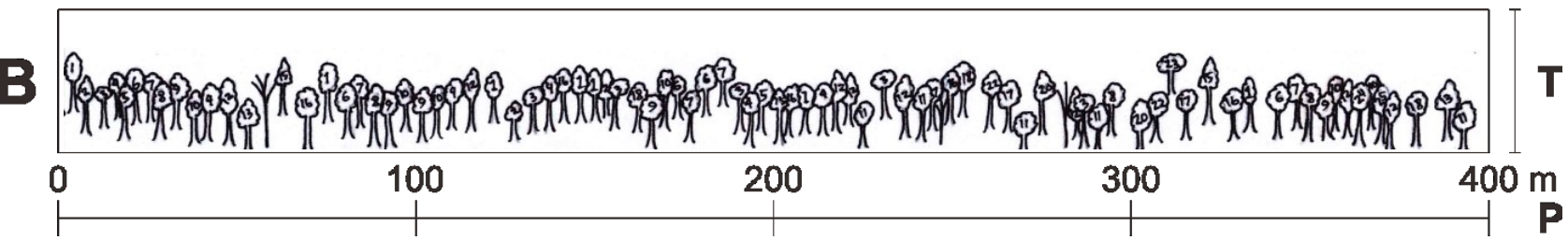

Gambar 6. Profil vegetasi Habitat 3 Siamang, Symphalangus syndactyilus, di HL Register 28 Pematang Neba Keterangan: A = Profil vegetasi secara horizontal (kerapatan tajuk), B = Profil vegetasi secara vertikal (tinggi pohon dan kerapatan pohon), Bidang areal pengamatan $\mathrm{P}=$ panjang $400 \mathrm{~m}, \mathrm{~L}=$ lebar $20 \mathrm{~m}$, dan $\mathrm{T}=$ tinggi pohon $14 \mathrm{~m}-27 \mathrm{~m}$

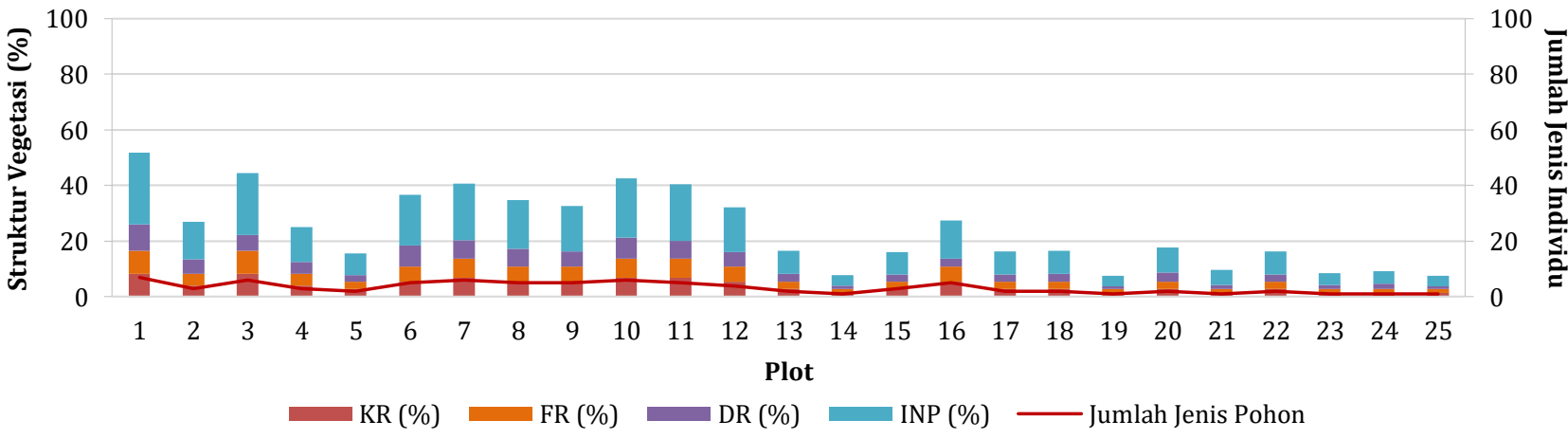

Gambar 7. Grafik Jumlah Jenis Pohon, Kerapatan Relatif, Frekuensi Relatif, Dominansi Relatif, dan INP antar plot yang terdapat di Habitat 3 HL Register 28 Pematang Neba

Berdasarkan pengamatan pada Habitat 2, terdapat duabelas jenis tumbuhan yang dijadikan sebagai tempat bermain dan beristirahat siamang, di antaranya adalah pulai (Alstonia scholaris), bambu (Bamboo sp.), waru (Talipariti tiliaceum), gamal (Gliricidia sepium), anggrong (Irema orientalis), pasang (Quercus sundaica), winong (Tetrameles nudiflora), bendo (Artocarpus elasticus), cempaka (Michelia champacca), ketapang (Terminalia catappa), mindi (Melia azedarach), randu hutan (Ceiba pentandra $L$ ). Sedangkan tujuh jenis tumbuhan yang dimakan siamang yaitu aren (Arenga pinnata), walek angin (Mallotus paniculatus), jengkol (Pitchelobium lobatum), rambutan hutan (Nephelium mutabile), petai cina (Leucaena leucocephala), matoa (Pometia pinnata) dan salam (Eugenia polyantha). Profil vegetasi pada Habitat 3 dapat menggambarkan stratifikasi tajuk Habitat 3, yang dapat menunjukkan efektifitas pergerakan siamang. Pepohonan yang tinggi dan memiliki tajuk cukup lebar memudahkan siamang untuk berpindah tempat dengan melakukan pergerakan di cabang-cabang pohon tersebut. 
Tabel 1. Indeks Keanekaragaman (Shannon-Wienner) pada ketiga Habitat di HL Register 28 Pematang Neba

\begin{tabular}{cccccc}
\hline No & Habitat & $\begin{array}{c}\text { Indeks keanekaragaman }\left(\boldsymbol{H}^{\prime}\right) \\
\text { Lokasi Makan }\end{array}$ & $\begin{array}{c}\text { Indeks keanekaragaman }\left(\boldsymbol{H}^{\prime}\right) \\
\text { Lokasi Tidur dan Bermain }\end{array}$ & $\begin{array}{c}\boldsymbol{H}^{\prime} \\
\text { Total }\end{array}$ & $\begin{array}{c}\text { Luas Areal } \\
\text { Pengamatan }\left(\mathbf{m}^{2}\right)\end{array}$ \\
\hline 1. & Habitat 1 & 1,953 & 2,301 & 2,905 & 14.000 \\
2. & Habitat 2 & 1,661 & 2,410 & 2,762 & 10.000 \\
3. & Habitat 3 & 2,223 & 2,453 & 3,066 & 8.000 \\
\hline
\end{tabular}

Sumber: Data Primer 2017

Namun pada habitat ini terdapat jarak (Gambar 6) yang membuat siamang terganggu dalam beraktivitas. Jarak tersebut dapat dilihat dari kelimpahan pohon yang rendah yaitu hanya berkisar 3,81-25,91\% (Gambar 7). Struktur vegetasi Habitat 3 berada pada strata tengah yaitu dengan tinggi pohon 14-27 m.

INP tertinggi dimiliki oleh pohon nomor 1 yaitu pohon suren (Toona sureni) (Gambar 7). Hal tersebut menunjukkan bahwa pohon suren memiliki dominansi yang tinggi pada Habitat 3 sekaligus menunjukkan bahwa suren mempunyai tingkat kesesuaian terhadap tempat tumbuh (daya adaptasi) dan daya kompetisi yang lebih baik dibandingkan dengan jenis lain pada lahan tersebut (Erwin et al., 2017).

Berdasarkan pengamatan pada Habitat 3, terdapat empatbelas jenis tumbuhan yang dijadikan sebagai tempat bermain dan beristirahat siamang, yaitu (Tonna sureni), pulai (Alstonia scholaris), kerai payung (Filicium decipiens), bambu (Bamboo sp.), waru (Talipariti tiliaceum), gamal (Gliricidia sepium), anggrong (Irema orientalis), pasang (Quercus sundaica), winong (Tetrameles nudiflora), bendo (Artocarpus elasticus), cempaka (Michelia champacca), ketapang (Terminalia catappa), mindi (Melia azedarach), randu hutan (Ceiba pentandra L). Sedangkan sebelas jenis tumbuhan yang dimakan siamang yaitu aren (Arenga pinnata), walek angin (Mallotus paniculatus), jengkol (Pitchelobium lobatum), rambutan hutan (Nephelium mutabile), petai cina (Leucaena leucocephala), matoa (Pometia pinnata), gondang (Ficus fariegata), suren (Toona sureni), pala (Myristica fragrans Houtt), kenanga (Cananga odorata), dan kemiri (Aleurites moluccanus). Bagian dari tumbuhan tersebut yang dimakan oleh siamang adalah daun, buah dan bunga.

Kelimpahan jenis pakan, pohon tidur dan pohon bermain pada ketiga habitat siamang di HL Register 28 Pematang Neba dapat diketahui melalui indeks keanekaragaman, indeks nilai penting (INP) dan indeks kesamaan komunitas (IKK).

Indeks keanekaragaman menunjukkan keragaman suatu spesies yang ada pada lokasi penelitian. Kriteria nilai indeks keanekaragaman Shannon-Wiener $\left(H^{\prime}\right)$ yaitu, $H^{\prime} \leq 1$ : keanekaragaman rendah, $1<H^{\prime}<3$ : keanekaragaman sedang dan $H^{\prime} \geq 3$ : keanekaragaman tinggi (Odum, 1971; Fachrul, 2007).

Indeks keanekaragaman spesies pada Habitat 1 dan Habitat 2 tergolong dalam kriteria sedang, sedangkan untuk Habitat 3 tergolong kriteria tinggi (Tabel 1). Habitat 3 tergolong tinggi karena pada Habitat 3 jumlah pohon yang ada lebih banyak dibandingkan Habitat 1 dan Habitat 2. Perbedaan tersebut salah satunya karena perbedaan luas areal penelitian yang dapat menentukan perbedaan nilai indeks keanekaragaman jenis (Sari, 2014), selain adanya aktivitas manusia di sekitar lokasi penelitian yang merupakan faktor paling bepengaruh pada perbedaan nilai keanekaragaman jenis antar habitat (Yudha et al., 2014).

Faktor lingkungan terpenting dari primata adalah kelimpahan dan distribusi sumber pakan (Yuliana, 2011). Jenis pohon yang digunakan untuk bermain dan tidur pun berada dalam katagori sedang. Hal ini menunjukkan bahwa pada ketiga habitat siamang di HL Register 28 Pematang Neba ini masih tergolong sesuai untuk habitat siamang.

Tabel 2. INP jenis pakan, pohon tidur dan pohon bermain pada Habitat 1, Habitat 2 dan Habitat 3 di HL Register 28 Pematang Neba

\begin{tabular}{cccc}
\hline \multirow{2}{*}{ Jenis } & \multicolumn{3}{c}{ INP (\%) } \\
\cline { 2 - 4 } & Habitat 1 & Habitat 2 & Habitat 3 \\
\hline A & 130,813 & 135,948 & 122,98 \\
B & 169,167 & 164,022 & 177,05 \\
\hline Sumber: & & &
\end{tabular}

Sumber: Data Primer 2017

Berdasarkan Tabel 2 dapat dilihat bahwa INP jenis pakan pada Habitat 1, Habitat 2, dan Habitat 3 berada pada katagori sedang. Pakan merupakan hal penting yang harus tersedia untuk Siamang karena akan mempengaruhi perilaku dan kondisi tubuhnya (Yuliana, 2011). Potensi pakan satwa dipengaruhi oleh kondisi fisik maupun kondisi biotik dari suatu habitat, apabila suatu habitat mengalami gangguan maka akan berpengaruh besar terhadap sumber pakan dan keberadaan populasi satwa (Violita et al., 2015).

Indeks kesamaan komunitas (IKK) menggambarkan tingkat kesamaan struktur dan komposisi jenis dari tegakan yang dibandingkan. Nilai indeks kesamaan berkisar antara $0-100 \%$. Kriteria yang digunakan menurut Odum (1971) yaitu, IKK < $50 \%$ rendah, IKK > 50\% tinggi.

Tabel 3. Indeks Kesamaan Komunitas pada Ketiga Habitat di HL Register 28 Pematang Neba

\begin{tabular}{|c|c|c|c|}
\hline No & Habitat & $\begin{array}{c}\text { Indeks Kesamaan } \\
\text { Komunitas (\%) }\end{array}$ & Kriteria \\
\hline & dengan Habitat 2 & 81 & Tinggi \\
\hline & dengan Habitat 3 & 69 & Tinggi \\
\hline & dengan Habitat 3 & 72 & Tinggi \\
\hline
\end{tabular}

Sumber: Data Primer 2017

Berdasarkan Tabel 3 dapat diketahui bahwa habitat yang diperbandingkan memiliki indeks kesamaan komunitas yang tinggi, yaitu $>50 \%$. Odum (1996) menyatakan bahwa semakin besar nilai indeks kesamaan komunitas untuk setiap habitat maka semakin tinggi tingkat kesamaannya. 
Tabel 4. Kesamaan jenis pohon yang ada pada Habitat 1, Habitat 2, dan Habitat 3 di HL Register 28 Pematang Neba

\begin{tabular}{|c|c|c|c|c|}
\hline \multirow{2}{*}{ No } & \multirow{2}{*}{ Komunitas } & \multicolumn{3}{|c|}{ Habitat } \\
\hline & & 1 & 2 & 3 \\
\hline 1. & Aren $(\text { Arenga pinnata })^{1}$ & $\checkmark$ & $\checkmark$ & $\checkmark$ \\
\hline 2. & Walek Angin (Mallotus paniculatus) ${ }^{1}$ & $\checkmark$ & $\checkmark$ & $\checkmark$ \\
\hline 3. & Gamal (Gliricidia sepium) ${ }^{2,3}$ & $\checkmark$ & $\checkmark$ & $\checkmark$ \\
\hline 4. & Bambu (Bamboo sp. $)^{3}$ & $\checkmark$ & $\checkmark$ & $\checkmark$ \\
\hline 5. & Kemiri (Aleurites moluccanus $)^{1}$ & $\checkmark$ & - & $\checkmark$ \\
\hline 6. & Jengkol (Pitchelobium lobatum) ${ }^{1}$ & $\checkmark$ & - & $\checkmark$ \\
\hline 7. & Anggrong (Irema orientalis) ${ }^{2,3}$ & $\checkmark$ & $\checkmark$ & - \\
\hline 8. & Bayur (Pterospermum javanicum $)^{2}$ & $\checkmark$ & $\checkmark$ & - \\
\hline 9. & Pasang (Quercus sundaica $)^{2,3}$ & $\checkmark$ & $\checkmark$ & $\checkmark$ \\
\hline 10. & Rambutan Hutan (Nephelium mutabile $)^{1}$ & $\checkmark$ & $\checkmark$ & $\checkmark$ \\
\hline 11. & Winong (Tetrameles nudiflora) ${ }^{2,3}$ & $\checkmark$ & $\checkmark$ & $\checkmark$ \\
\hline 12. & Petai Cina (Leucaena leucocephala) ${ }^{1}$ & $\checkmark$ & $\checkmark$ & $\checkmark$ \\
\hline 13. & Bendo (Artocarpus elasticus) ${ }^{2,3}$ & $\checkmark$ & $\checkmark$ & $\checkmark$ \\
\hline 14. & Cempaka (Michelia champaca) ${ }^{2}$ & $\checkmark$ & $\checkmark$ & $\checkmark$ \\
\hline 15. & Ketapang (Terminalia catappa) ${ }^{2}$ & $\checkmark$ & $\checkmark$ & $\checkmark$ \\
\hline 16. & Matoa (Pometia pinnata) ${ }^{1}$ & $\checkmark$ & $\checkmark$ & $\checkmark$ \\
\hline 17. & Mindi (Melia azedarach) ${ }^{2,3}$ & $\checkmark$ & $\checkmark$ & - \\
\hline 18. & Pulai (Alstonia scholaris) ${ }^{2}$ & - & $\checkmark$ & $\checkmark$ \\
\hline 19. & Salam (Eugenia polyantha) ${ }^{1,3}$ & - & $\checkmark$ & - \\
\hline 20. & Waru (Talipariti tiliaceum) ${ }^{2,3}$ & - & $\checkmark$ & $\checkmark$ \\
\hline 21. & Suren (Toona sureni) 1,2 & - & - & $\checkmark$ \\
\hline 22. & Medang (Litsea ferrugenia) ${ }^{3}$ & - & - & $\checkmark$ \\
\hline 23. & Kenanga (Cananga odorata $)^{1}$ & - & - & $\checkmark$ \\
\hline 24. & Kerai Payung (Felicium decipiens) ${ }^{2,3}$ & - & - & $\checkmark$ \\
\hline 25. & Pala (Myristica fragrans Houtt) ${ }^{1}$ & - & - & $\checkmark$ \\
\hline 26. & Bayas (Oncosperma horidum) $)^{2,3}$ & - & - & $\checkmark$ \\
\hline 27. & Gondang (Ficus variegata) 1,3 & $\checkmark$ & - & $\checkmark$ \\
\hline 28. & Rotan (Daemonorops rubra) ${ }^{3}$ & - & - & $\checkmark$ \\
\hline \multirow[t]{2}{*}{29.} & Randu Hutan (Ceiba pentandra L) ${ }^{3}$ & - & $\checkmark$ & $\checkmark$ \\
\hline & Jumlah Pohon & 18 & 19 & 25 \\
\hline
\end{tabular}

Sumber: Data Primer 2017. Keterangan: ${ }^{1}=$ Pohon sumber pakan, ${ }^{2}=$ Pohon tempat tidur, ${ }^{3}=$ Pohon tempat bermain

Hal ini karena rendahnya variasi kondisi lingkungan, baik fisik, kimia, maupun interaksi antarspesies di sepanjang areal penelitian akibatnya tingkat kesamaan komunitas vegetasi termasuk dalam kategori tinggi, sehingga apabila siamang berpindah ke habitat lainnya di HL Register 28 ini akan mudah menemukan pepohonan yang biasa dijadikan untuk pohon tidur, pohon bermain dan pohon pakan.

Berdasarkan pengamatan, antara Habitat 1 dengan Habitat 2, Habitat 1 dengan Habitat 3 dan Habitat 2 dengan Habitat 3, terdapat 14 jenis pohon yang sama dari dari 29 jenis yang ada, sehingga memungkinkan siamang untuk berpindah dari habitat satu ke habitat yang lainnya. Menurut Barbour et al. (1987), kondisi mikrositus yang relatif homogen akan ditempati oleh individu dari jenis yang sama, karena spesies tersebut secara alami telah mengembangkan mekanisme adaptasi dan toleransi terhadap habitatnya. Loveless (1983) mengemukakan bahwa faktor lain yang menentukan kehadiran suatu tumbuhan atau komunitas tumbuhan tidak hanya mencakup kondisi fisik, tetapi juga hewan dan manusia yang mempunyai pengaruh besar terhadap tumbuhan.

\section{KES I M P U L A N}

Struktur dan profil vegetasi habitat HL Register 28 Pematang Neba menunjukkan bahwa jarak antarpohon mempengaruhi aktivitas siamang baik dalam mencari makan, istirahat, dan bermain. INP jenis pakan pada Habitat 1 sebesar 130,813\%, Habitat 2 sebesar 135,948\%, Habitat 3 sebesar 122,98\%, dan ketiganya berada pada katagori sedang. Indeks keanekaragaman pada Habitat 1 sebesar 2,905, Habitat 2 sebesar 2,762 yang termasuk dalam kategori sedang dan Habitat 3 sebesar 3,066 yang menunjukkan keragaman jenis dalam katagori tinggi. Indeks kesamaan komunitas antara Habitat 1 dengan Habitat 2 sebesar 81\%, Habitat 1 dengan Habitat 3 sebesar 69\% dan Habitat 2 dengan Habitat 3 sebesar $72 \%$. Ketiga habitat tersebut termasuk dalam katagori tinggi sehingga memungkinkan siamang berpindah ke habitat lainnya.

\section{U C A P A N TERIMAKASIH}

Penulis mengucapakan terimakasih yang sebesarbesarnya kepada KPHL Register 28 Pematang Neba.

\section{DAFT AR REFERENSI}

Bangun TM, Mansjoer SS, Bismark M. 2009. Populasi dan habitat Ungko (Hylobates agilis) di Taman Nasional Batang Gadis, Sumatera Utara. Jurnal Primatologi Indonesia. 1:1410-5373.

Barbour GM, JK Burk, Pitts WD. 1987. Terrestrial plant ecology. New York: The Benyamin/Cummings Publishing Company, Inc.

Departemen Kehutanan. 1999. Undang-Undang Republik Indonesia Nomor 41 Tahun 1999 Tentang Kehutanan.

Desi, Linda R, Winarti I. 2017. Struktur dan profil vegetasi habitat kukang Kalimantan (Nycticebus menagensis) pelepasliaran yayasan IAR Indonesia di HL Gunung Tarak. Jurnal Protobiont. 6(1):1-9. 
Erwin, Bintoro A, Rusita. 2017. Keragaman vegetasi di blok pemanfaatan hutan pendidikan konservasi terpadu (HPKT) Tahura Wan Abdul Rachman, Provinsi Lampung. Jurnal Sylva Lestari. 5(3):1-11.

Fachrul MF. 2007. Metode sampling bioekologi. Jakarta: Bumi Aksara.

Heyne K. 1987. Tumbuhan berguna Indonesia. Jilid I dan II. Terjemahan. Badan Litbang Kehutanan. Cetakan I. Koperasi Karyawan Departemen Kehutanan Jakarta Pusat.

Indriyanto. 2006. Ekologi hutan. Jakarta: Bumi Aksara.

Iskandar E. 2007. Habitat dan populasi owa Jawa (Hylobates moloch) di Taman Nasional Gunung Halimun-Salak, Jawa Barat [disertasi]. Sekolah Pascasarjana, Institut Pertanian Bogor. Bogor.

Kwatrina RT, Kuswanda W, Setyawati T. 2013. Sebaran dan kepadatan populasi siamang (Symphalangus syndactylus Raffles, 1821) di Kecamatan Dolok Sipirok dan sekitarnya, Sumatera Utara. Jurnal Penelitian Hutan dan Konservasi Alam. 10(1):8191.

Larasati S [internet]. 2009. Mari kita mengenal primata: [diakses: 03 September 2016] dari http://wulanprimataloversblogspot. com.

Loveless AR. 1983. Prinsip-prinsip biologi tumbuhan untuk daerah tropik 2. Jakarta: Gramedia.

Mawazin, Subiakto A. 2013. Keanekaragaman dan komposisi jenis permudaan alam hutan rawa gambut bekas tebangan di Riau. Indonesian Forest Rehabilitation Journal. 1(1):59-73.

Geissmann T, Nijman V. 2006. Calling in wild silvery gibbons (Hylobates moloch) in Java, Indonesia: behavior, phylogeny, and conservation. Am J Primatol. 68(1):1-19.

Odum EP. 1971. Fundamentals of ecology. (Terjemahan Tjahjono Samingan. 1993. Ed. B. Srigandono. Dasar-dasar ekologi). Yogyakarta: Gadjah Mada University Press. 697 p.

Odum, E.P. 1996. Dasar-dasar ekologi (T. Samingan, Terjemahan). Yogyakarta: Gadjah Mada University Press.

Sari EM, Harianto SP. 2015. Studi kelompok siamang (Hylobates syndactylus) di Repong Damar Pahmungan pesisir barat. Jurnal Sylva Lestari. 3(3):85-94.
Sari IN, Nurdjali B, Erianto. 2014. Keanekaragaman jenis ampibi (ordo Anura) dalam kawasan HL Gunung Ambawang Kecamatan Kubu Kabupaten Kubu Raya. Jurnal Hutan Lestari. 2(1):116-125.

Setiadi D. 1998. Keterkaitan profil vegetasi sistem agroforestry kebun campur dengan lingkungannya. Disertasi. Bogor: Institut Pertanian Bogor, Program Pascasarjana, Jurusan Pengelolaan Sumber Daya Alam dan Lingkungan.

Smith RL. 1977. Element of ecology. New York: Harper \& Row. Publisher.

Supriatna J, Wahyono EH. 2000. Panduan lapang primata Indonesia. Jakarta: Yayasan Obor.

Sutisna U. 1981. Komposisi jenis hutan bekas tebangan di Batulicin, Kalimantan Selatan. Deskripsi dan analisis Laporan 328. Bogor: Balai Penelitian Hutan.

Suyanto A, Sinaga MH, Saim A. 2009. Biodiversitas mamalia di Tesso Nilo, Propinsi Riau, Indonesia. Zoo Indonesia. 18(2):79-88.

Tiyawati A, Harianto SP, Widodo Y. 2016. Kajian perilaku dan analisis kandungan gizi pakan drop in siamang (Hylobates syndactylus) di Taman Agro Satwa dan Wisata Bumi Kedaton. Jurnal Sylva Lestari. 4(1):107-114.

Violita CY, Setiawan A, Rustiati EL. 2015. Ukuran kelompok simpa (Presbytis melalophos) di hutan Desa Cugung kesatuan pengelolaan hutan lindung model Gunung Rajabasa Lampung Selatan. Jurnal Sylva Lestari. 3(3):11-18.

Yudha DS, Eprilurahman R, Trijoko, Alawi MF, Tarekat A. 2014. Keanekaragaman jenis katak dan kodok (ordo Anura) di sepanjang Sungai Opak Propinsi Daerah Istimewa Yogyakarta. Jurnal Biologi.18(2):52-59.

Yuliana R. 2011. Analisis habitat siamang (Hylobathes syndactilus) di Repong Damar Pekon Pahmungan Kecamatan Pesisir Tengah Lampung Barat [skripsi]. Lampung: Universitas Lampung.

Zahra NL. 2016. Studi populasi siamang (Simphalangus Syndactilus) di HL Register 25 Pematang Tanggang [skripsi]. Jurusan Kehutanan Universitas Lampung. Lampung. 